\title{
Stereoselective $\beta$-Mannosylation via Anomeric $O$-Alkylation: Formal Synthesis of Potent Calcium Signal Modulator Acremomannolipin A
}

\author{
Xiaohua Li,* Nader Berry, Kevin Saybolt, Uddin Ahmed, Yue Yuan \\ Department of Natural Sciences, University of Michigan-Dearborn, 4901 Evergreen Road, Dearborn, Michigan 48128, United States.
}

\section{ARTICLE INFO}

Article history:

Received

Received in revised form

Accepted

Available online

Keywords:

$\beta$-Mannosylation

Anomeric $O$-Alkylation

Synthesis

Acremomannolipin A

\section{ABSTRACT}

Stereoselective $\beta$-mannosylation has been investigated via cesium carbonate-mediated anomeric $O$-alkylation of $\mathrm{D}$-mannose-derived lactol with various electrophiles. It was found that electrophiles bearing trifluoromethanesulfonate (triflate) as the leaving group are most reactive. In addition, a highly efficient formal synthesis of potent calcium signal modulator acremomannolipin A has been achieved using this $\beta$-mannosylation method.

2013 Elsevier Ltd. All rights reserved.
The glycolipid acremomannolipin A (1) was isolated from a filamentous fungus Acremonium strictum. ${ }^{1}$ Structurally, acremomannolipin A contains a D-mannopyranoside $\beta$-linked to a D-mannitol and all the hydroxyls in the mannose are acylated with saturated aliphatic acids (Figure 1). Therefore, the D-mannose moiety is made hydrophobic, whereas the Dmannitol portion is hydrophilic. The structure of acremomannolipin A was elucidated on the basis of intensive spectroscopic analyses as well as its degradation studies. Biologically, acremomannolipin A showed the interesting activity at $200 \mathrm{nM}$ enabling calcineurin deletion mutant cells to grow in the presence of $\mathrm{Cl}^{-}$, which would be caused by calcium signal modulating. ${ }^{1}$ As a potential calcium signal modulator, acremomannolipin $\mathrm{A}$ is considered an attractive target for biologists as well as synthetic chemists as acremomannolipin A and its synthetic analogs may be of significance for therapeutic and biotechnological purposes.

The structural features of acremomannolipin A have posed significant difficulties for the total synthesis, mainly due to the presence of a $\beta$-mannoside which is known to be one of the most synthetically challenging glycosidic linkages. ${ }^{2}$ Previously, acremomannolipin A (1) was first synthesized by Muraoka and co-workers in 2013 (Scheme 1). ${ }^{3}$ Based on Crich $\beta$-mannosylation protocol, ${ }^{4}$ key intermediate $\beta$ mannoside 4 was obtained from 4,6- $O$-benzylidene-protected D-mannose donor 2 and acceptor 3 in $71 \%$ yield $(\beta / \alpha=30 / 1)$. Later, Muraoka and co-workers also prepared 1'-epi- acremomannolipin A, the $\alpha$-anomer of acremomannolipin A, which showed reduced activity. ${ }^{5}$ In 2015 , the same group also prepared five homologs of acremomannolipin A bearing alditols of different length and found that the length of the alditol side chain was a crucial determinant for the potent calcium signal modulating activity. ${ }^{6}$ Early 2015 , Li and coworkers reported another total synthesis of acremomannolipin A in which key intermediate $\beta$-mannoside 7 was obtained via gold(I)-catalyzed glycosylation ${ }^{7}$ between 4,6- $O$-benzylideneprotected D-mannose-derived ortho-alkynylbenzoate donor 5 and acceptor 6 in $85 \%$ yield $(\beta / \alpha=13 / 1){ }^{8}$ In 2016 , the Toshima group described the third total synthesis of acremomannolipin $A$ in which key intermediate $\beta$-mannoside 10 was obtained via borinic acid-catalyzed glycosylation between 1,2-anhydromannose donor 8 and acceptor 9 in $99 \%$ yield ( $\beta$ only). ${ }^{9}$

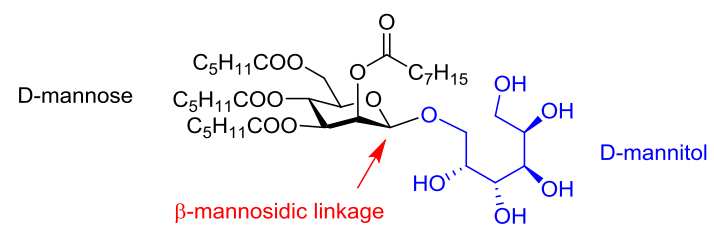

Figure 1. The structure of acremomannolipin A (1). 


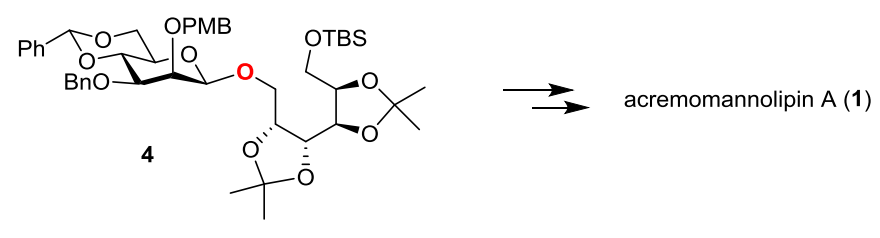

2. $\mathrm{Li}$
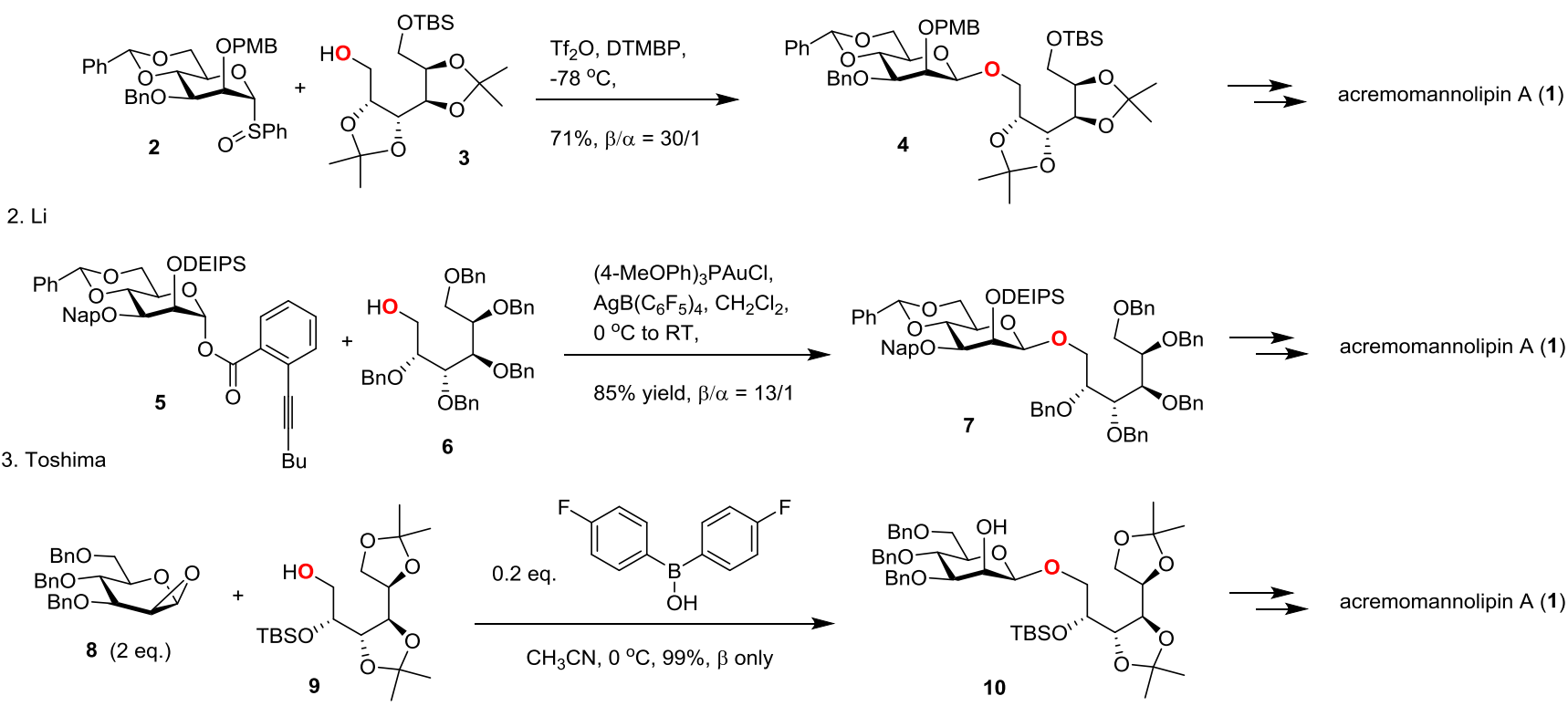

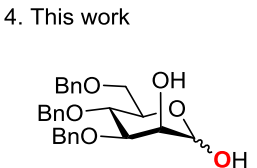

11
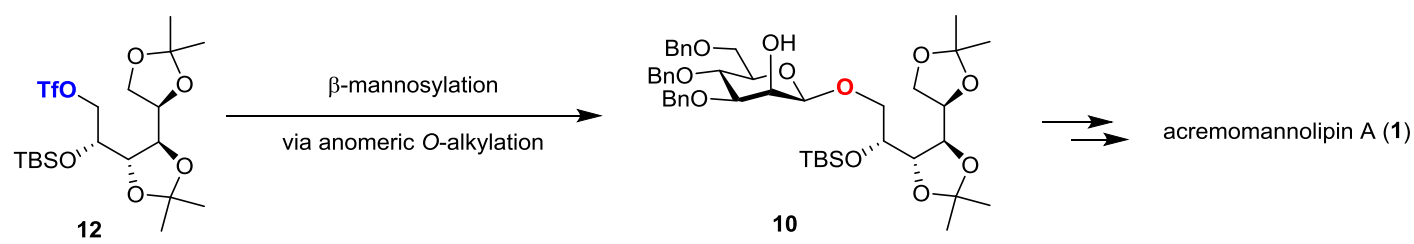

Scheme 1. Previous synthesis of acremomannolipin A and our strategy.

Early in 2016 we disclosed a new method for stereoselective construction of $\beta$-mannosides via cesium carbonate-mediated anomeric $O$-alkylation of D-mannosederived lactols. ${ }^{10}$ In this Communication, we would like to report our efforts in the synthesis of acremomannolipin A in which the key intermediate $\beta$-mannoside $\mathbf{1 0}$ was prepared from known D-mannose-derived lactol $\mathbf{1 1}^{11}$ and D-mannitolderived primary triflate $\mathbf{1 2}$ via cesium carbonate-mediated anomeric $O$-alkylation.

In our previous report, ${ }^{10}$ only sugar-derived primary and secondary alkyl triflates, e.g. 14, were studied as electrophiles for cesium carbonate-mediated anomeric $O$-alkylation with Dmannose-derived lactols. For example, when C6-primary triflate 14 was employed, $\beta$-D-mannoside 16 was obtained in $93 \%$ yield ( $\beta$ only, entry 1$).{ }^{10} \mathrm{We}$ wondered if other primary electrophiles bearing different leaving groups other than triflates would also react with lactol $\mathbf{1 1}$ in this type of $\beta$ mannosylation. As shown in Table 1, it was found that only the use of excess 1-iodopentane and $\mathrm{Cs}_{2} \mathrm{CO}_{3}$ afforded desired $\beta$-D-mannoside 17 in $21 \%$ yield ( $\beta$ only, entry 2 ), while there was no detectable product when 1-bromopentane, n-pentyl mesylate or tosylate was employed (entries 3-5). Elevation of the reaction temperature to $50{ }^{\circ} \mathrm{C}$ or use of other solvents did not improve the reaction outcome. Use of methyl iodide gave methyl $\beta$-D-mannoside $\mathbf{1 8}$ in $71 \%$ yield ( $\beta$ only, entry 6 ). Over-methylation at $\mathrm{O} 2$ could be seen if the reaction was allowed to proceed longer. When activated alkyl halides, such as allyl bromide and benzyl bromide, were used, corresponding desired $\beta$-D-mannoside 19 and 20 were produced in $94 \%$ and $64 \%$ yields, respectively ( $\beta$ only, entries 7 and 8 ). These studies indicated that non-activated primary alkyl triflates are required to react with mannose-derived lactols in the presence of cesium carbonate for efficient synthesis of $\beta$-mannosides.
Table 1. Studies of stereoselective $\beta$-mannosylation via anomeric $O$-alkylation involving various electrophiles. ${ }^{a}$
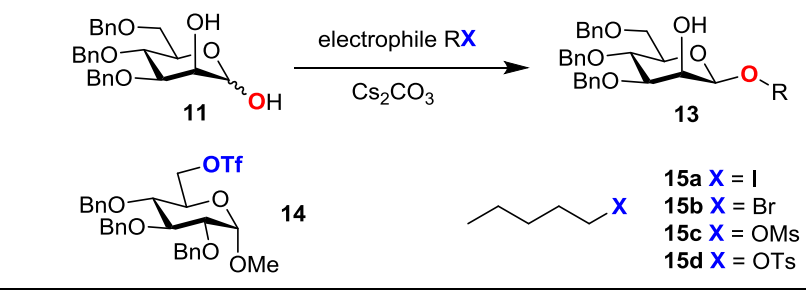

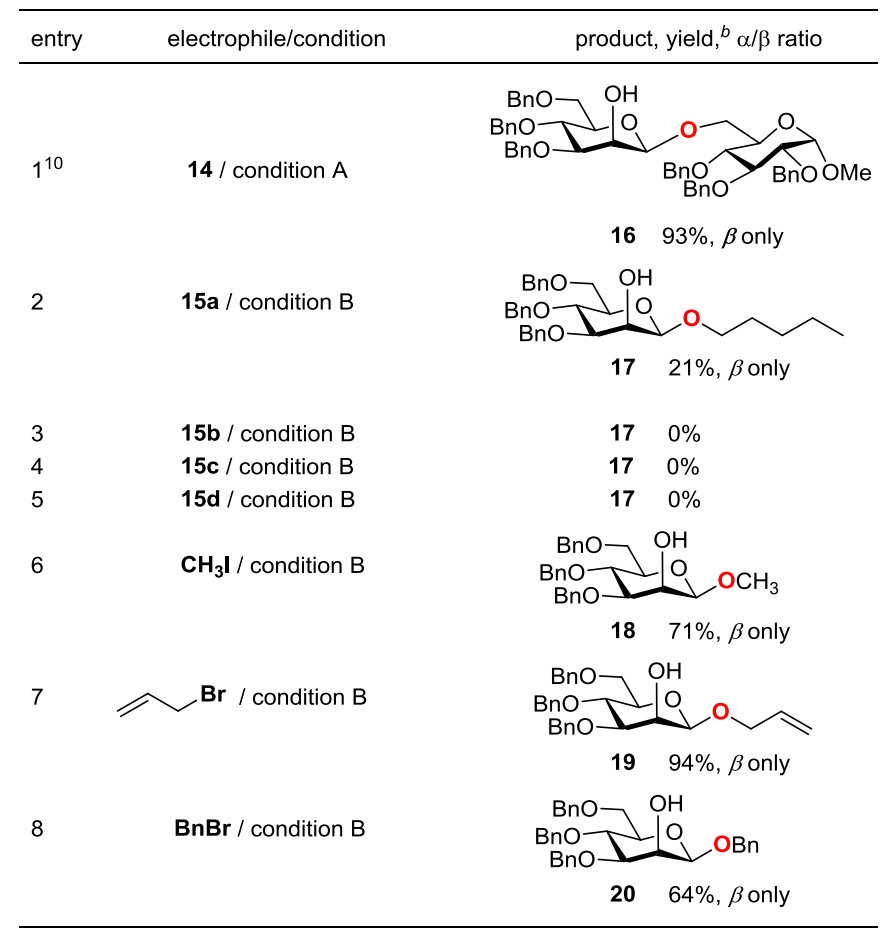


${ }^{a}$ Condition A: 11 (1.0 eq.), 14 (1.5 eq.), $\mathrm{Cs}_{2} \mathrm{CO}_{3}$ (2.0 eq.), $\mathrm{ClCH}_{2} \mathrm{CH}_{2} \mathrm{Cl}, 40{ }^{\circ} \mathrm{C}, 24 \mathrm{~h}$; Condition $\mathrm{B}$ : 11 (1.0 eq.), electrophile (2.5 eq.), $\mathrm{Cs}_{2} \mathrm{CO}_{3}$ (3.0 eq.), $\mathrm{ClCH}_{2} \mathrm{CH}_{2} \mathrm{Cl}, 40{ }^{\circ} \mathrm{C}$, 24 h. $^{b}$ Isolated yield.

Next, we aimed at the synthesis of acremomannolipin A. Starting from D-mannitol, the triflate acceptor $\mathbf{1 2}$ can be prepared in six steps by adopting the known procedures. ${ }^{9,12}$ As shown in Scheme 2, conversion of commercially available Dmannitol 21 into its corresponding tri-acetonide (88\%) followed by regioselective deprotection of one of the terminal acetonides afforded diol $22(91 \%){ }^{12}$ Regioselective benzylation $^{11}$ of the primary alcohol of $22(73 \%)$ followed by silylation ${ }^{9}$ of the secondary alcohol gave rise to $\mathbf{2 3}(85 \%)$. Next, removal of the benzyl ether of $\mathbf{2 3}$ via palladiumcatalyzed hydrogenolysis furnished the known primary alcohol 24 in $83 \%$ yield. ${ }^{9}$ This primary alcohol 24 was then subjected to standard triflation (triflic anhydride, pyridine,dichloromethane, $0{ }^{\circ} \mathrm{C}$ ) to afford desired triflate $\mathbf{1 2}$ in $96 \%$ yield. ${ }^{13}$ Under our recently developed optimal $\beta$ mannosylation condition, ${ }^{10}$ known D-mannose-derived lactol $\mathbf{1 1}{ }^{11}$ reacted with triflate acceptor $\mathbf{1 2}$ in dichloroethane in the presence of cesium carbonate at $40{ }^{\circ} \mathrm{C}$ for 24 hours afforded the desired key $\beta$-mannoside $\mathbf{1 0}$ in $87 \%$ yield ( $\beta$ only). ${ }^{14}$ The $\mathrm{R}_{f},{ }^{1} \mathrm{H}$ and ${ }^{13} \mathrm{C}$ NMR, optical rotation, and HRMS data of our synthesized $\beta$-mannoside $\mathbf{1 0}$ were found to be identical to those reported in the literature. ${ }^{9}$ For the synthesis of acremomannolipin A (1), $\beta$-mannoside 10 would just need to undergo standard acylations and deprotections. ${ }^{9}$ Thus, our efforts constitute a highly efficient formal synthesis of acremomannolipin A (1).
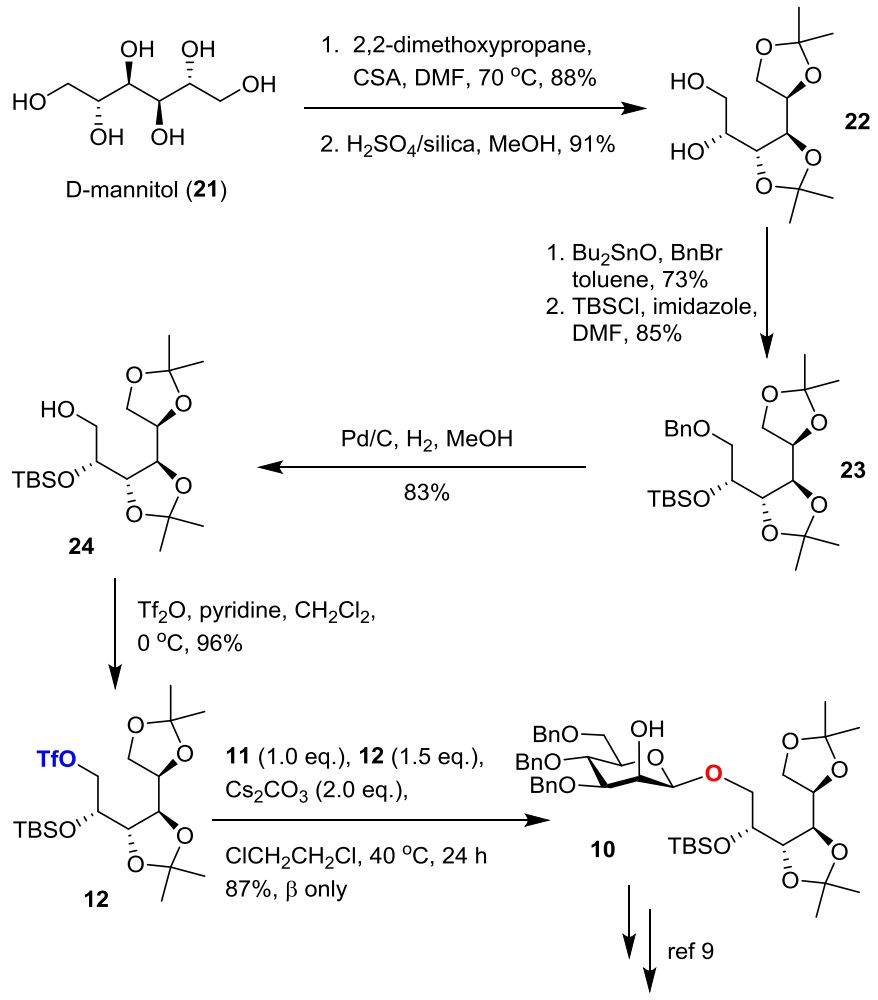

acremomannolipin A (1)

Scheme 2. Synthesis of acremomannolipin A.

In conclusion, stereoselective $\beta$-mannosylation has been studied via cesium carbonate-mediated anomeric $O$-alkylation of D-mannose-derived lactol with various electrophiles. It was found that electrophiles bearing triflate as the leaving group are most reactive and efficient for this type of $\beta$ mannosylation. In addition, a highly efficient formal synthesis of potent calcium signal modulator acremomannolipin $\mathrm{A}$ has been achieved using this $\beta$-mannosylation method.

\section{Acknowledgments}

We are grateful to National Science Foundation (CHE1464787) and University of Michigan-Dearborn for supporting this research. We would also like to thank Professor Jianglong Zhu (Department of Chemistry and Biochemistry, University of Toledo) for helpful discussions.

\section{References and notes}

1 Sugiura, R.; Kita, A.; Tsutsui, N.; Muraoka, O.; Hagihara, K.; Umeda, N.; Kunoh, T.; Takada, H.; Hirose, D. Bioorg. Med. Chem. Lett. 2012, 22, 6735-6739.

2 (a) Nigudkar, Swati S.; Demchenko, Alexei V. Chem. Sci. 2015, 6, 2687-2704. (b) Ishiwata, A.; Lee, Y. J.; Ito, Y. Org. Biomol. Chem. 2010, 8, 3596-3608. (c) Barresi, F.; Hindsgaul, O. Modern Methods in Carbohydrate Synthesis; Khan, S. H.; O'Neill, R. A. Eds.; Harwood Academic Publishers: Amsterdam, 1996; 251-276. (d) Toshima, K.; Tatsuta, K. Chem. Rev. 1993, 93, 15031531. (e) Paulsen, H. Angew. Chem., Int. Ed. 1982, 21, $155-173$

3 Tsutsui, N.; Tanabe, G.; Kita, A.; Sugiura, R.; Muraoka, O. Tetrahedron Lett. 2013, 54, 451-453.

4 (a) Crich, D.; Sun, S. J. Org. Chem. 1996, 61, 4506-4507.

(b) Crich, D.; Sun, S. Tetrahedron 1998, 54, 8321-8348.

(c) Crich, D.; Sun, S. J. Am. Chem. Soc. 1997, 119, 1121711223.

5 Tsutsui, N.; Tanabe, G.; Gotoh, A.; Kita, A.; Sugiura, R.; Muraoka, O. Tetrahedron 2013, 69, 9917-9930.

6 Tsutsui, N.; Tanabe, G.; Morita, N.; Okayama, Y.; Kita, A.; Sugiura, R.; Muraoka, O. Bioorg. Med. Chem. 2015, 23, 3761-3773.

7 (a) Li, Y.; Yang, Y.; Yu, B. Tetrahedron Lett. 2008, 49, 3604-3608. (b) Yu, B.; Sun, J.; Yang, X. Acc. Chem. Res. 2012, 45, 1227-1236.

8 Sun, P.; Wang, P.; Zhang, Y.; Zhang, X.; Wang, C.; Liu, S.; Lu, J.; Li, M. J. Org. Chem. 2015, 80, 4164-4175.

9 Tanaka,M.; Nashida, J.; Takahashi, D.; Toshima, K. Org. Lett. 2016, 18, 2288-2291.

10 Nguyen, H.; Zhu, D.; Li, X.; Zhu, J. Angew. Chem., Int. Ed. 2016, 55, 4767-4771.

11 Jonke, S.; Liu, K.-G.; Schmidt, R. R. Chem. Eur. J. 2006, 12, 1274-1290.

12 Vidyasagar, A.; Sureshan, K. M. Eur. J. Org. Chem. 2014, 2349-2356. 
13 Preparation of triflate 12: To known alcohol $\mathbf{2 4}^{9}$ (50.0 mg, $0.13 \mathrm{mmol}$ ) in $1.0 \mathrm{~mL}$ anhydrous $\mathrm{CH}_{2} \mathrm{Cl}_{2}$ cooled at $0{ }^{\circ} \mathrm{C}$ was added anhydrous pyridine $(0.39 \mathrm{mmol}, 0.03 \mathrm{~mL})$ followed by the addition of triflic anhydride $(0.2 \mathrm{mmol}$, $0.03 \mathrm{~mL}$ ). The mixture was stirred at $0{ }^{\circ} \mathrm{C}$ for 30 minutes before being quenched with water. The crude reaction mixture was diluted with $\mathrm{CH}_{2} \mathrm{Cl}_{2}$ and washed sequentially with saturated $\mathrm{CuSO}_{4}$ aqueous solution, water, and brine. The organic solution was dried over sodium sulfate, filtered, and concentrated in vacuo to afford $64 \mathrm{mg}$ of the desired triflate 12 (96\% yield) which was sufficiently pure for the next step. ${ }^{1} \mathrm{H}$ NMR $\left(400 \mathrm{MHz}, \mathrm{CDCl}_{3}\right) \delta 4.65-4.62$ (dd, $J=3.7,10.3 \mathrm{~Hz}, 1 \mathrm{H}), 4.56-4.51$ (dd, $J=7.0,10.3 \mathrm{~Hz}$, $1 \mathrm{H}), 4.26-4.23(\mathrm{~m}, 1 \mathrm{H}), 4.19-4.15(\mathrm{dd}, J=6.2,8.4 \mathrm{~Hz}$, $1 \mathrm{H}), 4.09-4.04(\mathrm{~m}, 1 \mathrm{H}), 4.02-3.99(\mathrm{dd}, J=3.2,7.0 \mathrm{~Hz}$, $1 \mathrm{H}), 3.97-3.93$ (dd, $J=5.9,8.4 \mathrm{~Hz}, 1 \mathrm{H}), 3.92-3.89$ ( $J=7.2$, $15.0 \mathrm{~Hz}, 1 \mathrm{H}), 1.43$ (s, 3H), 1.42 (s, 3H), 1.37 (s, 3H), 1.36 (s, 3H), 0.94 (s, 9H), $0.16(\mathrm{~s}, 3 \mathrm{H}), 0.15(\mathrm{~s}, 3 \mathrm{H}) .{ }^{13} \mathrm{C}$ NMR $\left(100 \mathrm{MHz}, \mathrm{CDCl}_{3}\right) \delta 112.3,109.9,109.0,82.7,81.0,80.3$, $73.2,73.1,70.2,67.7,66.8,26.8,26.4,25.9,25.7,25.2$, $24.7,24.5$

14 Synthesis of key $\beta$-mannoside 10: To a mixture of known D-mannose-derived lactol $\mathbf{1 1}^{11}$ (45 mg, $0.1 \mathrm{mmol}$ ), sugarderived triflate 12 (76 $\mathrm{mg}, 0.15 \mathrm{mmol})$, and cesium carbonate $(65 \mathrm{mg}, \quad 0.2 \mathrm{mmol})$ was added 1,2dichloroethane $(1.0 \mathrm{~mL})$. The reaction mixture was stirred at $40^{\circ} \mathrm{C}$ for 24 hours under Argon. The crude reaction mixture was diluted with $1 \mathrm{~mL}$ dichloromethane and directly purified by preparative thin layer chromatography (hexanes: $\mathrm{EtOAc}=1: 1$ ) to furnish $70 \mathrm{mg}$ of $\beta$-mannoside 7 (87\% yield). The $\mathrm{R}_{f},{ }^{1} \mathrm{H}$ and ${ }^{13} \mathrm{C} \mathrm{NMR}$, optical rotation, and HRMS data of our synthetic $\beta$-mannoside $\mathbf{1 0}$ were found to be identical to those reported in the literature. ${ }^{9}$ 